\title{
High Serum 25-Hydroxyvitamin D Levels Are Associated with Pediatric Sepsis
}

\author{
Gokhan Aydemir, ${ }^{1}$ Ferhat Cekmez, ${ }_{1}^{1}$ Gokhan Kalkan, ${ }^{2}$ M.Kursat Fidanci, ${ }^{1}$ \\ Guven Kaya, ${ }^{1}$ Abdulbaki Karaoglu, ${ }^{3}$ Cihan Meral, ${ }^{1}$ İbrahim Arzıman, \\ Ferhan Karademir, ${ }^{1}$ Ganime Ayar, ${ }^{5}$ Ramiz Coskun Gunduz ${ }^{5}$ and \\ Selami Suleymanoglu ${ }^{1}$ \\ ${ }^{1}$ Department of Pediatrics, GMMA Medical Faculty, Istanbul, Turkey \\ ${ }^{2}$ Department of Pediatrics, Gazi University, Ankara, Turkey \\ ${ }^{3}$ Department of Pediatrics, GMMA Medical Faculty, Ankara, Turkey \\ ${ }^{4}$ Department of Emergency Medicine, GMMA Medical Faculty, Ankara, Turkey \\ ${ }^{5}$ Pediatric Service, Ankara Childrens Hematology Oncology Education and Research Hospital, Pediatric Intensive \\ Care Unit, Ankara, Turkey
}

Despite major advances in intensive care, sepsis continues to be a major cause of morbidity and mortality. Vitamin $D$ is involved in various physiologic functions, including cellular responses during infection and inflammation. The aim of this study was to evaluate diagnostic value of 25 -hydroxyvitamin $D$ in childhood sepsis because it can be fatal if diagnosis delayed. The study included 40 children with sepsis and 20 children without sepsis (control group). We included only the patients with high probable sepsis, judged by clinical and laboratory findings, including positive blood culture. Blood samples were collected from patients with sepsis before treatment (pre-treatment group) and 48-72 hours later (post-treatment group). Treatment varied from ampicillin-sulbactam to cephalosporin. Blood samples were collected from control group once on admission. Serum 25-hydroxyvitamin D levels were significantly higher in sepsis (pre-treatment group) than control group $(74 \pm 8 \mathrm{ng} / \mathrm{ml}$ vs. $28 \pm 12 \mathrm{ng} / \mathrm{ml}, p=0.01)$ and the serum 25-hydroxyvitamin D levels were decreased to $44 \pm 5 \mathrm{ng} / \mathrm{ml}(p=0.01)$ after treatment. Moreover, we found significant positive correlation between 25-hydroxyvitamin $D$ and each of well-know sepsis markers, C-reactive protein, tumor necrosis factor- $\alpha$ and interleukin-6. A cut-off point of $20 \mathrm{ng} / \mathrm{mL}$ for serum 25 -hydroxyvitamin D showed $84 \%$ sensitivity and $76 \%$ specificity for sepsis diagnosis. This is the first study evaluating the diagnostic role of vitamin $D$ in pediatric sepsis, thereby suggesting that serum 25-hydroxyvitamin $\mathrm{D}$ level can be used as a diagnostic marker for sepsis with high sensitivity and specificity.

Keywords: acute phase reactant; child; diagnosis; hydroxyvitamin D; sepsis

Tohoku J. Exp. Med., 2014 December, 234 (4), 295-298. C 2014 Tohoku University Medical Press

\section{Introduction}

Sepsis is a clinical syndrome, described by many physiologic changes of systemic inflammation on the body, which are due to the proven or suspected infection. Because of difficulties in determining the infections, many biomarkers are being searched for early diagnosis (Goldstein et al. 2005), but none of them could have reached enough achievement up to now. Thus, much efforts have been focused to find effective and sensitive markers for sepsis.

Vitamin D plays an important role in many different physiologic functions. The well-known major function of vitamin $\mathrm{D}$ is to maintain calcium and phosphorus homeo- stasis and bone mineralization, but currently, many studies have focused on the novel roles of vitamin D in glucose metabolism, endothelial functions and immune modulation (Nierman and Mechanick 1998; Grant 2009; Lee et al. 2009; Braun et al. 2011). Although the mechanism of vitamin D on enhanced immunity is complex, it might have an important role in the optimal function of the innate immune system by inducing antimicrobial peptides in epithelial cells, neutrophils and macrophages (Kempker et al. 2012; Clancy et al. 2013). Besides kidney, 1,25-dihydroxyvitamin $\mathrm{D}_{3}$ is also produced by immune system cells especially during infection. During infection, pathogen associated molecular patterns are recognized by Toll-like receptors expressed on immune system cells especially macrophages (Gong and

Received May 27, 2014; revised and accepted November 13, 2014. Published online December 17, 2014; doi: 10.1620/tjem.234.295. Turkey. Correspondence: Ferhat Cekmez, M.D., GMMA Medical Faculty, Department of Pediatrics, Division of Neonatology, 06018 Ankara, e-mail: ferhat_cocuk@hotmail.com 
Wei 2014), and then 25-hydroxyvitamin- $\mathrm{D}_{3}-1-\alpha-$ hydroxylase (CYP27B1) catalyzes synthesis of 1,25-dihydroxyvitamin $\mathrm{D}_{3}$ in immune cells, triggered by toll-like receptors. 1,25-dihydroxyvitamin $\mathrm{D}_{3}$ enhances the expression of B-defensin gene that encodes the cathelicidin and B-defensin. Both peptides are intracellular mediators of antiviral and antibacterial activity (Wang et al. 2004). Production of 1,25-dihydroxyvitamin $\mathrm{D}_{3}$ is further increased by interferon $\gamma$. In addition to cathelicidin and B-defensin, 1,25-dihydroxyvitamin $\mathrm{D}_{3}$ induces other important antimicrobial factors, including reactive oxygen species, nitric oxide synthase and active form of interleukin- $1 \beta$ that trigger the beginning of inflammation cascade (Verway et al. 2013).

In this study, we evaluated the predictive value of serum 25-hydroxyvitamin D level and its correlation with commonly used acute phase reactants, such as C-reactive protein (CRP), tumor necrosis factor- $\alpha(\mathrm{TNF} \alpha)$ and interleukin-6 (IL-6) in children with sepsis Early diagnosis is vital for childhood sepsis because it can be more mortal than adult sepsis.

\section{Materials and Methods}

Subjects

The present study enrolled children, between 1 and 16 years old, admitted to pediatric service, pediatric infectious service, pediatric intensive care in Gazi University between 2012 and 2013. Children with diabetes mellitus, parathyroid, bone, renal, gastrointestinal and other chronic disorders were excluded. According to Gitto et al. (2001) the children were classified into four groups as group 1 (high probable sepsis), group 2 (probable sepsis), group 3 (possible sepsis) and group 4 (no sepsis) (Table 1). A total of 128 children were included in the study, and 20 of them were control group (group
4 in Table 1). In addition to high probable sepsis, we used only data of patients with proven positive blood culture, and thus we had excluded 68 children with high probable sepsis but with negative blood culture.

Ethical approval has been received from Diskap1 Training Hospital Ethic Committee and informed consents have been obtained before the blood samples were taken.

\section{Blood samples}

Blood was collected from children on the first day of sepsis (pre-treatment) and 48-72 hours later (post-treatment). Treatment choices varied: ceftriaxon, vancomycin, gentamicin, ampicillin or combination of them. Control group patients were free of sepsis, and their samples were taken on admission. After clotting, the serum was separated and immediately explored for analyses. Whole blood cell count (WBC) was performed using an automatic counter, Cell Dyn 3,700. IL-6 was measured by enzyme-linked immunosorbent test. $\mathrm{TNF} \alpha$ was measured using commercial ELISA kits. Levels of 25-OHD were determined using Shimadzu LC-20AT model High Performance Liquid Chromatography (HPLC) system (Shimadzu Scientific Instruments, SSI, Kyoto, Japan) attached with a UV-detector at Biochemistry Laboratory of Gulhane Military Medical Faculty.

\section{Statistical analysis}

Descriptive data were expressed as mean \pm standard deviation. Chi-square or Fisher's Exact test was used to compare categorical variables, and the Wilcoxon Rank Sum test was used to compare continuous variables. The correlations among numerical data were analysed by the Pearson correlation coefficient (r). A $p$ value $<0.05$ was considered statistically significant. Statistical analysis was performed with SPSS 12.0 software (IBM, Chicago, IL, USA).

\section{Results}

There were 20 children without sepsis (control) and 40

Table 1. Criteria employed for defining the sepsis score.

\begin{tabular}{ll}
\hline \multicolumn{1}{c}{ Groups } & \multicolumn{1}{c}{ Criteria } \\
\hline Group 1 (high probable sepsis) & At least 3 sepsis-related clinical signs ${ }^{\mathrm{a}}$ \\
& CRP $>1 \mathrm{mg}$ per $100 \mathrm{ml}$ \\
& At least 2 other altered serum parameters in addition to CRP \\
& Blood culture; negative or positive \\
\hline Group 2 (probable sepsis) & Less than sepsis-related clinical signs ${ }^{\mathrm{a}}$ \\
& CRP $>1 \mathrm{mg}$ per $100 \mathrm{ml}$ \\
& At least 2 other altered serum parameters in addition to CRP \\
& Blood culture; negative \\
\hline Group 3 (possible sepsis) & Less than sepsis-related clinical signs \\
& CRP $<1$ mg per 100 ml \\
& Less than other altered serum parameters \\
& Blood culture; negative \\
\hline Group 4 (no sepsis) & No sepsis related clinical signs ${ }^{\mathrm{a}}$ \\
& CRP $<1$ mg per $100 \mathrm{ml}$ \\
& No altered serum parameters \\
\hline
\end{tabular}

CRP, C-reactive protein.

aSepsis-related clinical signs: temperature instability, need for supplemented oxygen, need for ventilation, tachycardia/bradicardia, hypotension, feeding intolerance, abdominal distention.

bSerum parameters other than CRP: white blood cell count, absolute neutrophil count, platelet count (Gitto et al. 2001). 
Table 2. Characteristics and laboratory results of the children in control group and study group.

\begin{tabular}{lccc}
\hline & $\begin{array}{c}\text { Control Group } \\
(n=20)\end{array}$ & \multicolumn{2}{c}{ Sepsis Group $(n=40)$} \\
post-treatment
\end{tabular}

*Control vs. Sepsis Group (pre-treatment) $p<0.05$.

**Sepsis Group (pre-treatment) vs. Sepsis Group (post-treatment) $p<0.05$.

Table 3. Pearson correlation results between 25-hydroxyvitamin $\mathrm{D}$ and other markers.

\begin{tabular}{lc}
\hline & $\begin{array}{c}25 \text {-hydroxyvitamin D } \\
(\mathrm{ng} / \mathrm{ml})\end{array}$ \\
\hline White blood cell count $/ \mathrm{mm}^{3}$ & $0.33^{*}$ \\
$\mathrm{CRP}(\mathrm{mg} / \mathrm{dl})$ & $0.39 * *$ \\
$\mathrm{TNF} \alpha(\mathrm{pg} / \mathrm{ml})$ & $0.47 * *$ \\
$\mathrm{IL}-6(\mathrm{pg} / \mathrm{ml})$ & $0.42^{* *}$ \\
$25-\mathrm{hydroxy}$ itaminD $(\mathrm{ng} / \mathrm{mL})$ & 1 \\
\hline & $*$ Correlation is significant at the 0.05 level (2-tailed). \\
$* *$ Correlation is significant at the 0.01 level (2-tailed).
\end{tabular}

children with sepsis. Table 2 shows the clinical demographics, outcome and laboratory findings of study and control groups. There were significant differences between control and sepsis (pre-treatment) for $\operatorname{WBC}(11,200 \pm 3,000$ $\mathrm{mm}^{3}$ and $21,000 \pm 3,050 \mathrm{~mm}^{3}, p=0.02$, respectively), for CRP levels $(1.7 \pm 1.1 \mathrm{mg} / \mathrm{dl}$ and $15 \pm 6 \mathrm{mg} / \mathrm{dl}, p=0.01$, respectively), for TNF $\alpha$ levels $(16 \pm 11 \mathrm{pg} / \mathrm{ml}$ and $51 \pm 14$ $\mathrm{pg} / \mathrm{ml}, p=0.01$, respectively), for IL-6 levels $(8 \pm 3 \mathrm{pg} / \mathrm{ml}$ and $66 \pm 13 \mathrm{pg} / \mathrm{ml}, p=0.01$, respectively), and for 25 -hydroxyvitamin D levels $(28 \pm 12 \mathrm{ng} / \mathrm{ml}$ and $74 \pm 8 \mathrm{ng} /$ $\mathrm{ml}, p=0.01)$.

There were significant differences between sepsis (pretreatment) and sepsis (post-treatment) for WBC $(21,000 \pm$ $3,050 \mathrm{~mm}^{3}$ and $\left.17,300 \pm 2,600 \mathrm{~mm}^{3}, p=0.02\right)$, for CRP levels $(15 \pm 6 \mathrm{mg} / \mathrm{dl}$ and $7.1 \pm 2.3 \mathrm{mg} / \mathrm{dl}, p=0.01)$, for $\mathrm{TNF} \alpha$ levels $(51 \pm 14 \mathrm{pg} / \mathrm{ml}$ and $41 \pm 14 \mathrm{pg} / \mathrm{ml}, p=0.01)$, for IL-6 levels $(66 \pm 13 \mathrm{pg} / \mathrm{ml}$ and $25 \pm 6 \mathrm{pg} / \mathrm{ml}, p=0.01)$, and for 25-hydroxyvitamin D levels $(74 \pm 8 \mathrm{ng} / \mathrm{ml}$ and $44 \pm$ $5 \mathrm{ng} / \mathrm{ml}, p=0.01)$, respectively.

There were positive correlations between 25-hydroxyvitamin D and each of other markers: WBC, CRP, TNF $\alpha$ and IL-6 (Table 3). A cut-off point of $20 \mathrm{ng} / \mathrm{mL}$ for 25-hydroxyvitamin D showed $84 \%$ sensitivity and $76 \%$ specificity.

\section{Discussion}

Despite major advances in intensive care, sepsis con- tinues to be a major reason of morbidity and mortality. Inception of clinical symptoms is generally subtle, but sepsis may rapidly progress and worsen, and may cause death within hours. Because of these difficulties, it is vital to diagnose sepsis very early and accurately. However, despite so many biomarkers were studied for diagnosis up to now, none of laboratory tests has achieved enough rapid and reliable identification speciality of infected child (Sepanski et al. 2014).

In this study, we found that 25-hydroxyvitamin D level was significantly higher in pre-treatment group than posttreatment group or control group. In addition to bone mineralization, 25-hydroxyvitamin D has many other effects such as immune modulation, glucose metabolism and endothelial functions (Lee et al. 2009; Braun et al. 2011). The mechanical barrier of the skin and other epithelial surfaces constitute the first barrier against infections, and activated vitamin $\mathrm{D}$ has an important role in maintaining the integrity of epithelial cells (Gniadecki et al. 1997). Vitamin D also affects $\mathrm{T}$ helper (Th) cells 1 and 2 . Th2 differentiation is directly induced by vitamin $\mathrm{D}$ whereas it inhibits activation and differentiation of Th1 cells (Clancy et al. 2013). Vitamin D has a role in superoxide generation in monocytes by presumably increasing and prolonging the oxidative stress of monocytes (Levy and Malech 1991). It also prevents excessive production of inflammatory cytokines and facilitates neutrophil motility and phagocytosis (Youssef et al. 2011). Jeng et al. (2009) found that vitamin D stimulates the expression of endogenous antimicrobial peptides in immune cells modulating for immune response to different infections. Cells of the innate and adaptive immune system including macrophages, lymphocytes and dendritic cells express the vitamin $\mathrm{D}$ receptor (VDR) and response to stimulation by 1,25-dihydroxyvitamin $\mathrm{D}_{3}$ during infection (Adams and Hewison 2008). 1,25-dihydroxyvitamin $D_{3}$ enhances the expression of B-defensin gene that encodes the cathelicidin and B-defensin. Both peptides are intracellular mediators of antiviral and antibacterial activity (Wang et al. 2004). Cathelicidin, also known as LL-37, is one of endogenous antimicrobial peptides that have a defensive role against a wide spectrum of infectious agents including 
gram negative and positive bacteria, fungi and mycobacteria (Lee et al. 2014). Liu et al. (2006) showed that 1,25-dihydroxyvitamin $\mathrm{D}_{3}$ treatment of cultured macrophages infected with Myobacterium tuberculosis caused enhanced expression of cathelicidin. Cathelicidin is highly expressed at barrier sites including respiratory and colonic epithelium, saliva, skin and thus provides an important first line defense mechanism for the innate immune system to respond against infectious insults. Sadeghi et al. (2006) showed that vitamin $\mathrm{D}$ treatment in vitro has also been demonstrated to increase levels of systemic inflammatory cytokines such as TNF $\alpha$ and IL-6.

In this study, we found that 25-hydroxyvitamin $\mathrm{D}$ positively correlated with CRP, TNF $\alpha$ and IL-6. There are several cross-sectional studies in literature that showed strong relation between 25-hydroxyvitamin D deficiency and sepsis or mortality (Quraishi et al. 2014; Moromizato et al. 2014). In contrast, the present study is the first study that was made in same groups before and after treatment and found high level of 25-hydroxyvitamin D in pre-treatment group. We thought that 25-hydroxyvitamin D increases in sepsis to enhance anti-microbial peptide production and contribute to immune defence system, but patients with 25-hydroxyvitamin $\mathrm{D}$ deficiency can not increase the 1,25-dihydroxyvitamin $\mathrm{D}_{3}$ and indirectly $\mathrm{B}$-defensin and cathelicidin so that infection process may cause higher rate of morbidity and mortality.

In the light of these results, we suggest that 25-hydroxyvitamin D level can be used as an acute phase reactant in diagnosis of sepsis, similar to CRP, TNF $\alpha$ and IL-6. Future studies are needed to understand the role of 25-hydroxyvitamin D in both diagnosis and follow-up of sepsis.

\section{Conflict of Interest}

The authors declare no conflict of interest.

\section{References}

Adams, J.S. \& Hewison, M. (2008) Unexpected actions of vitamin D: new perspectives on the regulation of innate and adaptive immunity. Nat. Clin. Pract. Endocrinol. Metab., 4, 80-90.

Braun, A., Chang, D., Mahadevappa, K., Gibbons, F.K., Liu, Y., Giovannucci, E. \& Christopher, K.B. (2011) Association of low serum 25-hydroxyvitamin D levels and mortality in the critically ill. Crit. Care Med., 39, 671-677.

Clancy, N., Onwuneme, C., Carroll, A., McCarthy, R., McKenna, M.J., Murphy, N. \& Molloy, E.J. (2013) Vitamin D and neonatal immune function. J. Matern. Fetal Neonatal Med., 26, 639-646.

Gitto, E., Karbownik, M., Reiter, R.J., Tan, D.X., Cuzzocrea, S., Chiurazzi, P., Cordaro, S., Corona, G., Trimarchi, G. \& Barberi, I. (2001) Effects of melatonin treatment in septic newborns. Pediatr. Res., 50, 756-760.

Gniadecki, R., Gajkowska, B. \& Hansen, M. (1997) 1,25-dihydroxyvitamin D3 stimulates the assembly of adherens junctions in keratinocytes: involvement of protein kinase C. Endo- crinology, 138, 2241-2248.

Goldstein, B., Giroir, B. \& Randolph, A. (2005) International pediatric sepsis consensus conference: definitions for sepsis and organ dysfunction in pediatrics. Pediatr. Crit. Care Med., 6, 2-8.

Gong, J. \& Wei, T. (2014) Structure modeling of Toll-like receptors. Methods Mol. Biol., 1169, 45-53.

Grant, W.B. (2009) Solar ultraviolet-B irradiance and vitamin D may reduce the risk of septicemia. Dermatoendocrinol., $\mathbf{1}$, 37-42.

Jeng, L., Yamshchikov, A.V., Judd, S.E., Blumberg, H.M., Martin, G.S., Ziegler, T.R. \& Tangpricha, V. (2009) Alterations in vitamin D status and anti-microbial peptide levels in patients in the intensive care unit with sepsis. J. Transl. Med., 7, 28.

Kempker, J.A., Han, J.E., Tangpricha, V., Ziegler, T.R. \& Martin, G.S. (2012) Vitamin D and sepsis: An emerging relationship. Dermatoendocrinol., 4, 101-108.

Lee, C.J., Buznyk, O., Kuffova, L., Rajendran, V., Forrester, J.V., Phopase, J., Islam, M.M., Skog, M., Ahlqvist, J. \& Griffith, M. (2014) Cathelicidin LL-37 and HSV-1 corneal infection: peptide versus gene therapy. Transl. Vis. Sci. Technol., 3, 4.

Lee, P., Eisman, J.A. \& Center, J.R. (2009) Vitamin D deficiency in critically ill patients. N. Engl. J. Med., 360, 1912-1914.

Levy, R. \& Malech, H.L. (1991) Effect of 1,25-dihydroxyvitamin D3, lipopolysaccharide, or lipoteichoic acid on the expression of NADPH oxidase components in cultured human monocytes. J. Immunol., 147, 3066-3071.

Liu, P.T., Stenger, S., Li, H., Wenzel, L., Tan, B.H., Krutzik, S.R., Ochoa, M.T., Schauber, J., Wu, K., Meinken, C., Kamen, D.L., Wagner, M., Bals, R., Steinmeyer, A., Zügel, U., et al. (2006) Toll-like receptor triggering of a vitamin D-mediated human antimicrobial response. Science, 311, 1770-1773.

Moromizato, T., Litonjua, A.A., Braun, A.B., Gibbons, F.K., Giovannucci, E. \& Christopher, K.B. (2014) Association of low serum 25-hydroxyvitamin D levels and sepsis in the critically ill. Crit. Care Med., 42, 97-107.

Nierman, D.M. \& Mechanick, J.I. (1998) Bone hyperresorption is prevalent in chronically critically ill patients. Chest, 114, 1122-1128.

Quraishi, S.A., Bittner, E.A., Blum, L., Hutter, M.M. \& Camargo, C.A. Jr. (2014) Association between preoperative 25-hydroxyvitamin D level and hospital-acquired infections following Roux-en-Y gastric bypass surgery. JAMA Surg., 149, 112-118.

Sadeghi, K., Wessner, B., Laggner, U., Ploder, M., Tamandl, D., Friedl, J., Zügel, U., Steinmeyer, A., Pollak, A., Roth, E., Boltz-Nitulescu, G. \& Spittler, A. (2006) Vitamin D3 downregulates monocyte TLR expression and triggers hyporesponsiveness to pathogen-associated molecular patterns. Eur. J. Immunol., 36, 361-370.

Sepanski, R.J., Godambe, S.A., Mangum, C.D., Bovat, C.S., Zaritsky, A.L. \& Shah, S.H. (2014) Designing a pediatric severe sepsis screening tool. Front. Pediatr., 16, 56.

Verway, M., Bouttier, M., Wang, T.T., Carrier, M., Calderon, M., An, B.S., Devemy, E., McIntosh, F., Divangahi, M., Behr, M.A. \& White, J.H. (2013) Vitamin D induces interleukin-1 $\beta$ expression: paracrine macrophage epithelial signaling controls M. tuberculosis infection. PLoS Pathog., 9, e1003407.

Wang, T.T., Nestel, F.P., Bourdeau, V., Nagai, Y., Wang, Q., Liao, J., Tavera-Mendoza, L., Lin, R., Hanrahan, J.W., Mader, S. \& White, J.H. (2004) Cutting edge: 1,25-dihydroxyvitamin D3 is a direct inducer of antimicrobial peptide gene expression. $J$. Immunol., 173, 2909-2912.

Youssef, D.A., Miller, C.W., El-Abbassi, A.M., Cutchins, D.C., Cutchins, C., Grant, W.B. \& Peiris, A.N. (2011) Antimicrobial implications of vitamin D. Dermatoendocrinol., 3, 220-229. 